\title{
Iatrogenic vasospasm in carotid artery stent angioplasty with distal protection devices
}

\author{
Clemens M. Schirmer, M.D., DANiel A. HoIt, M.D., M.P.H., \\ ANd Adel M. MaleK, M.D., Ph.D. \\ Cerebrovascular and Endovascular Division, Department of Neurosurgery, Tufts-New England \\ Medical Center and Tufts University School of Medicine, Boston, Massachusetts
}

\begin{abstract}
Object. Distal protection devices (DPDs) have decreased the risk of embolic stroke among patients with carotid artery (CA) disease undergoing CA stent placement. The FilterWire EX is a first-generation fixed-basket DPD with a filter rigidly attached to a guidewire. Second-generation mobile-basket DPDs (RX Accunet or SpiderFX) allow movement of the filter relative to the guidewire and can thus reduce the potential for vessel irritation, vasospasm, or intimal injury during CA stent placement.

Methods. Stent angioplasty was attempted in 40 CAs (37 patients) using the fixed-basket FilterWire DPD, a second-generation mobile-basket DPD, or no protection in 12,6, and 22 arteries, respectively. Clinical presentation, angiographic details relating to the incidence of vasospasm or dissection, and clinical outcome data were recorded and analyzed.

Results. Vasospasm was associated with use of the fixed-basket FilterWire device (8 [67\%] of 12 cases) compared with the bare unfiltered guidewire group (3 [14\%] of 22) and the second-generation mobile-basket DPD group $(1[17 \%]$ of $6, p<0.004)$. Secondary angioplasty was also associated with intraprocedural vasospasm. In a multivariate analysis, FilterWire use was an independent risk factor for vasospasm $(\mathrm{p}<0.0003)$.

Conclusions. A high incidence of vasospasm was observed following CA stent placement procedures in which the fixed-basket FilterWire EX DPD was used but not in unprotected CA stent placement or procedures in which a second-generation mobile-basket DPD was used. Although this phenomenon was self-limited in all instances, vasospasm should be considered a risk of these devices and may predispose to more serious vascular injury. Coronary artery stent placement should be performed with a second-generation mobile-basket DPD to minimize the risks of embolic complications and iatrogenic vascular injury. (DOI: 10.3171/FOC/2008/24/2/E12)
\end{abstract}

\section{KEY Words - carotid artery disease - dissection • intimal injury - stent placement • vasospasm}

$\mathrm{C}$ AROTID artery stent placement has emerged as an important treatment option for the treatment of atherosclerotic disease of the cervical CCA and ICA in certain defined high-risk patient subsets. 2,6,9,20,23,28 Current guidelines favor the use of DPDs during CA stent placement because of the reduction of large-fragment emboli as well as overall distal embolic burden and associated stroke risk. ${ }^{8} 10,14,17,20,22,23,28,29$ Although both clinical and experimental studies have demonstrated a decrease in the stroke rate with DPDs, ${ }^{10,11,22}$ authors of a number of studies have reported iatrogenic complications of DPD use, including vasospasm and, in severe cases, intimal dissection.,19 The outward radial force of the basket component of the DPD against the vessel wall, which is necessary to achieve com-

Abbreviations used in this paper: $\mathrm{CA}=$ carotid artery $\mathrm{CAD}=\mathrm{CA}$ disease; $\mathrm{CCA}=$ common $\mathrm{CA} ; \mathrm{DPD}=$ distal protection device; ICA = internal CA;TIA = transient ischemic attack. plete apposition to the vessel, combined with axial frictional movements during angioplasty, stent deployment, and retrieval of the DPD has been proposed as a mechanism. ${ }^{18}$ Data that quantify the extent of the vessel wall damage in an ex vivo animal model have been previously reported. ${ }^{15}$

In this report we analyze a series of cases involving either unprotected CA stent placement with the use of a bare guidewire or filter-protected CA stent placement, with the use of either a first-generation fixed-basket DPD (FilterWire EX, Boston Scientific Corp.) or a second-generation mobile-basket DPD (RX Accunet, Abbott Vascular, or SpiderFX, ev3, Inc.). We correlate the incidence of intraprocedural iatrogenic vasospasm with the type of DPD and other patient-specific and periprocedural factors.

\section{Clinical Materials and Methods}

Between August 2001 and April 2007, CA stent angioplsty was attempted in 40 CAs in 37 consecutive patients 
TABLE 1

Demographic and clinical characteristics of 37 patients who underwent 40 CA stent placement procedures*

\begin{tabular}{lccccc}
\hline \hline \multicolumn{1}{c}{ Variable } & Total & $\begin{array}{c}\text { Bare Unfiltered } \\
\text { Guidewire }\end{array}$ & $\begin{array}{c}\text { Fixed-Basket } \\
\text { FilterWire EX }\end{array}$ & $\begin{array}{c}\text { Mobile-Basket } \\
\text { 2nd-Gen DPD } \dagger\end{array}$ & p Value \\
\hline $\begin{array}{l}\text { no. of procedures } \\
\text { age in yrs (mean } \pm \mathrm{SD})\end{array}$ & 40 & 22 & 12 & 6 & \\
$\begin{array}{l}\text { female sex } \\
\text { hx \& presentation }\end{array}$ & $71 \pm 10$ & $71 \pm 12$ & $73 \pm 9$ & $69 \pm 5$ & $<0.64$ \\
$\begin{array}{l}\text { stroke/TIA } \\
\text { previous CEA }\end{array}$ & $16(40)$ & $9(41)$ & $3(25)$ & $4(67)$ & $<0.23$ \\
$\begin{array}{l}\text { previous stent } \\
\text { asymptomatic }\end{array}$ & $20(50)$ & $11(50)$ & $6(50)$ & $3(50)$ & $<0.99$ \\
risk factors & $4(10)$ & $4(18)$ & 0 & 0 & $<0.16$ \\
$\quad \begin{array}{l}\text { bilateral disease } \\
\text { previous radiation }\end{array}$ & $1(3)$ & $1(5)$ & 0 & 0 & $<0.66$ \\
hx of myocardial ischemia & $20(50)$ & $11(50)$ & $6(50)$ & $3(50)$ & $<0.99$ \\
\hline
\end{tabular}

* Values represent numbers of patients $(\%)$ unless otherwise specified. CEA = carotid endarterectomy; gen = generation; hx = history; $\mathrm{SD}=$ standard deviation.

$\dagger$ Guidant Accunet in 3 procedures and SpiderFX in 3 procedures.

who had atherosclerotic CAD. In 22 cases (55\%) a standard 300-cm, 0.014-inch, bare unfiltered exchange guidewire was used; in 12 procedures $(30 \%)$ a $300-\mathrm{cm}$ first-generation fixed-basket DPD (FilterWire EX) was used, and in 6 cases $(15 \%)$ a second-generation mobile-basket DPD (RX Accunet, 3 cases; SpiderFX, 3 procedures) was used. Clinical presentation data, anatomical and procedural details relating to wire tip position, incidence of angiographic vasospasm, intimal injury or dissection, and clinical outcome data were recorded and analyzed in both groups. Table 1 summarizes the demographic information and presentation for all patients. All data were recorded and analyzed using JMP Version 5 (SAS Institute, Inc.). For statistical analysis, analysis of variance, t-tests, and chi-square tests were used, and a probability value of $<0.05$ was considered statistically significant.

\section{The FilterWire EX Distal Protection Device}

The fixed-basket FilterWire EX DPD consists of a distal polyurethane filter with pores sized between 80 and 100 $\mu \mathrm{m}$ that is mounted eccentrically on a 0.014 -inch steerable guidewire (Fig. 1A). The filter basket is fixed to a selfexpandable radiopaque nitinol loop that achieves apposition to the carotid vessel wall. The DPD basket is mounted on the guidewire via a spinner tube that permits steering of the guidewire when the filter is withdrawn inside the delivery sheath with a crossing profile of $3.8 \mathrm{~F}$, but with no freedom of movement along the wire axis. The use of the FilterWire DPD has been previously reported, ${ }^{3,8}$ and shortterm outcomes of a randomized trial have been published. ${ }^{27}$ In an ex vivo human atherosclerotic CA preparation, $100 \%$ of particles $>360 \mu \mathrm{m}$ in diameter and $93 \%$ of particles $>$ $80 \mu \mathrm{m}$ in diameter embolized following balloon angioplasty and stent placement were captured successfully by this DPD. ${ }^{16}$

\section{Second-Generation DPD}

\section{The RX Accunet}

The RX Accunet is a mobile-basket DPD with a nickeltitanium basket mounted on a steerable 0.014-inch guidewire of either 190- or 300-cm length. The filter consists of a membrane with a maximum pore size of $150 \mu \mathrm{m}$ supported by a basket (Fig. 1B). Radiopaque markers on

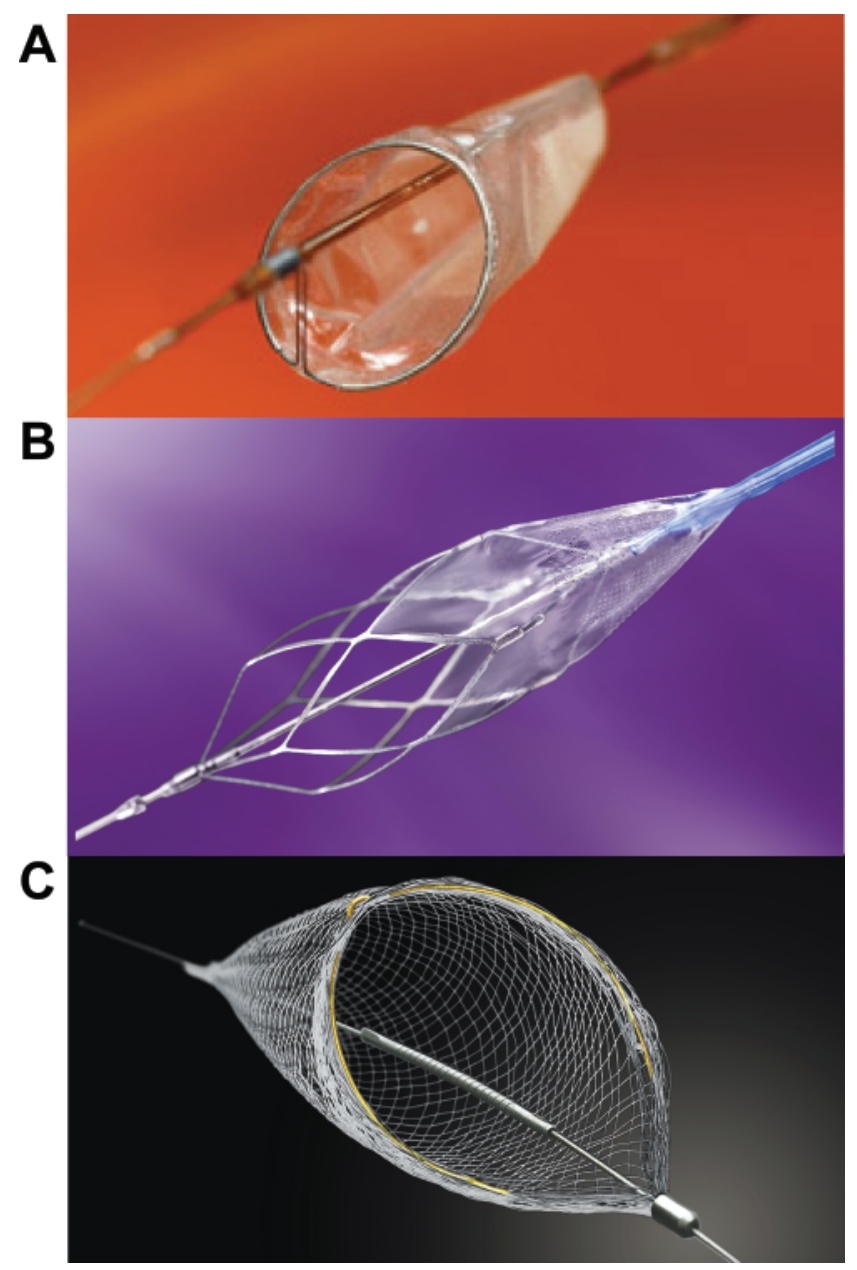

FIG. 1. Photographs of DPDs. A: FilterWire EX. B: RX Accunet. C: SpiderFX. 
TABLE 2

Angiographic and procedural results*

\begin{tabular}{lccccc}
\hline \hline \multicolumn{1}{c}{ Variable } & Total & $\begin{array}{c}\text { Bare Unfiltered } \\
\text { Guidewire }\end{array}$ & $\begin{array}{c}\text { Fixed-Basket } \\
\text { FilterWire EX }\end{array}$ & $\begin{array}{c}\text { Mobile-Basket } \\
\text { 2nd-Gen DPD } \dagger\end{array}$ & p Value \\
\hline no. of procedures & 40 & 22 & 12 & 6 & \\
pre-CAS stenosis (\%) & $81 \pm 9$ & $84 \pm 8$ & $80 \pm 10$ & $75 \pm 9$ & $<0.08$ \\
cervical CA loop & $12(30)$ & $8(36)$ & $4(33)$ & 0 & $<0.21$ \\
wire above C-1 (atlas) & $18(48)$ & $10(45)$ & $7(58)$ & $1(17)$ & $<0.22$ \\
vasospasm & $12(30)$ & $3(14)$ & $8(67)$ & $1(17)$ & $<0.004 \ddagger$ \\
intraarterial nitroglycerin & $4(10)$ & 0 & $3(25)$ & $1(17)$ & $<0.03 \ddagger$ \\
primary angioplasty & $33(83)$ & $19(86)$ & $12(100)$ & $2(33)$ & $<0.002 \ddagger$ \\
stent deployed & $37(93)$ & $20(91)$ & $12(100)$ & $5(83)$ & $<0.41$ \\
secondary angioplasty & $34(85)$ & $20(91)$ & $11(92)$ & $3(50)$ & $<0.04 \ddagger$ \\
\hline
\end{tabular}

$*$ Values represent numbers of procedures $(\%)$ unless otherwise specified. CAS = CA stent placement.

$\dagger$ Guidant Accunet in 3 cases and SpiderFX in 3 cases.

$\$$ Statistically significant.

the guidewire, filter basket, and delivery sheath aid in the positioning of the device in the vessel distal to the stenosis. The basket is mounted centrally on the guidewire, and the proximal attachment of the basket on the guidewire is free to move on the guidewire in a longitudinal fashion. The safety and efficacy of the RX Accunet DPD were established in a series of prospective, nonrandomized, multicenter, single-arm studies. ${ }^{7}$

\section{The SpiderFX}

The mobile-basket SpiderFX combines a windsockshaped nitinol mesh basket mounted eccentrically on a polytetrafluoroethylene-coated 0.014 -inch stainless-steel capture-wire. A proximal gold loop allows retrieval of the mesh basket and visualization of the mesh contour on fluoroscopic images and ensures wall apposition (Fig. 1C). The SpiderFX wire is designed to rotate independently and move slightly longitudinally in relation to the filter. The feasibility and use of the SpiderFX device have been previously reported in 30 patients $^{21}$ in anticipation of a larger multicenter trial to assess its safety and efficacy.

\section{Angioplasty and Stent Placement Procedure}

Carotid artery stent placement was carried out in each patient in the following standard fashion: In most cases a 6-F vascular sheath was inserted and a diagnostic catheter was used to selectively catheterize the CCA proximal to the stenosis. Following biplanar and 3D rotational measurements of the stenosis dimensions, either a DPD system or a bare guidewire was used to cross the lesion. When a DPD was used it was deployed in the high cervical ICA $\geq 15-20$ $\mathrm{mm}$ distal to the most distal end of the lesion in a suitable location based on the vessel curvature. Primary angioplasty was performed in the majority of cases (Table 2), followed by deployment of a stent (Precise Smart Stent, Cordis Corp.; Guidant Acculink stent, Abbott Vascular; or Protege stent, ev3, Inc.). After deployment of the stent, secondary angioplasty was performed if necessary to treat any significant residual stenosis or to aid in shaping the stent and embedding it into the vessel wall. The secondary angioplasty balloon was then deflated and removed. At this point, the DPD was retrieved, removed from the circulation, and inspected for collected debris. Biplanar and 3D rotational angiography were used to assess for residual stenosis, intimal damage, dissection, or branch occlusion of both the cervical and intracranial circulation.

\section{Results}

Carotid artery stent placement was successfully performed in 37 (93\%) of 40 cases; in 3 cases only primary angioplasty was performed and no stent could be successfully deployed. In 2 of these cases angioplasty was performed in unprotected fashion, and in the third case a second-generation DPD was used. In none of the 3 cases were there any complications related to iatrogenic vasospasm (Table 2).

A significantly higher incidence of iatrogenic vasospasm was detected among the first-generation fixed-basket FilterWire DPD group (8 [67\%] of 12; Fig. 2) when compared with the bare exchange wire group (3 [14\%] of 22, Fig. 3) or the group in which a second-generation mobilebasket DPD was used (1 [17\%] of 6 cases, $p<0.004$; Fig. 4). No significant differences were seen between the 2 groups with respect to age, sex, clinical presentation, presence of tortuous distal cervical CA segments, or distal wire tip position (Tables 1 and 2).

One instance of a non-flow-limiting dissection was observed in the bare exchange wire group. In this case stenting was not possible. The dissection was observed, but was not apparent on follow-up angiography 4 days later or 1 month later. In all occurrences, iatrogenic vasospasm resolved following administration of intraarterial nitroglycerine (4 cases, 10\%) or waiting before proceeding with the intervention. Nitroglycerin was more frequently administered in the FilterWire DPD group (3 [25\%] of 12 cases, $\mathrm{p}<0.03)$. Primary angioplasty and secondary angioplasty were more frequently performed in the FilterWire DPD group ( $\mathrm{p}<0.002$ and $\mathrm{p}<0.04$, respectively; Table 2 ). There were no embolic strokes in either group, and there was no between-groups difference in clinical outcome.

Univariate analysis of factors potentially related to vasospasm showed that the use of the FilterWire EX DPD (8 [67\%] of 12 cases, $p<0.004)$ and secondary angioplasty (12 [35\%] of 34 cases, $p<0.03)$ were significantly associated with iatrogenic vasospasm (Table 3 ).

In a stepwise logistic regression model the variables gender, cardiac risk factors, use of a fixed-basket FilterWire 
A

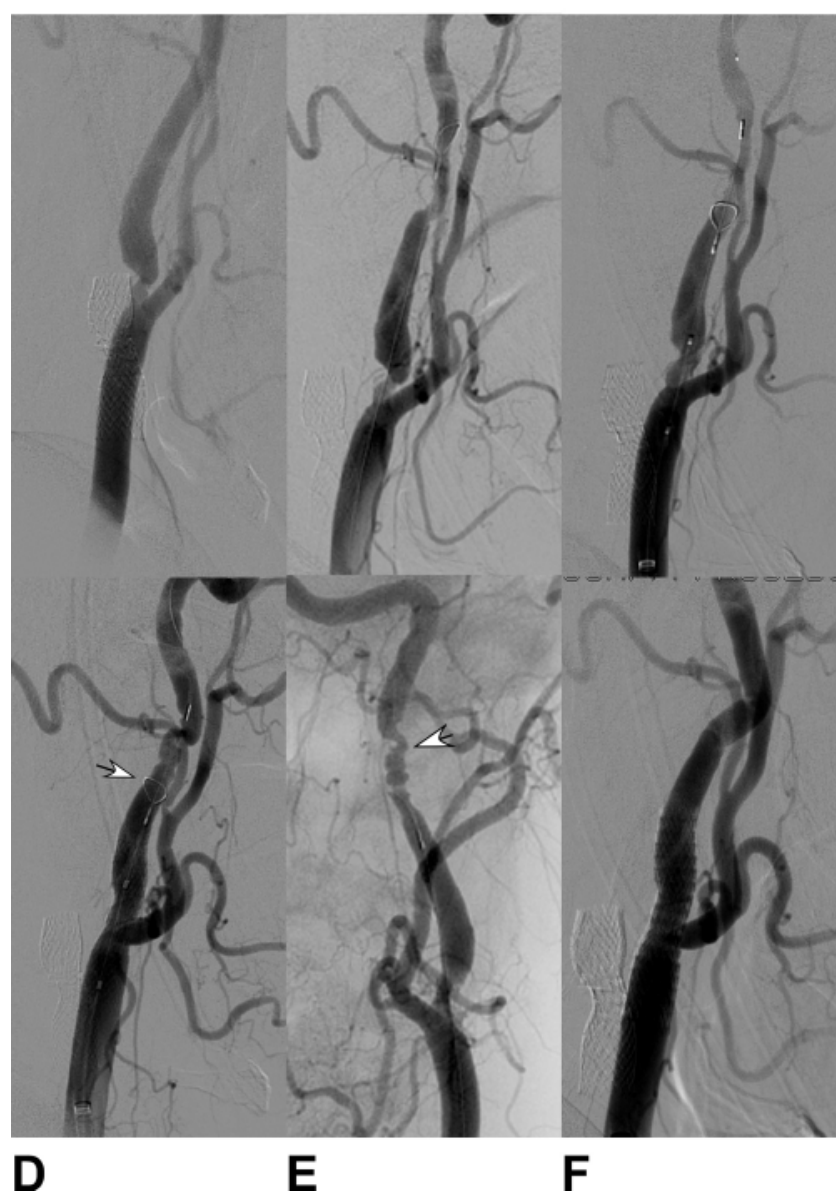

FIG. 2. Angiograms obtained in a 61-year-old woman with extensive cardiac risk factors and bilateral CA stenosis that was diagnosed during treatment of intracranial aneurysms. A: Singleplanar fluoroscopic view of a CCA injection showing an $80 \%$ stenosis of the proximal ICA. B and C: Biplane fluoroscopic views of the deployed FilterWire EX device showing good wall apposition. D and E: Single-plane fluoroscopic views of a CCA injection showing severe vasospasm (D) adjacent to the filter hoop and basket of the FilterWire EX during primary angioplasty with a Cordis Slalom $3 \times 20-\mathrm{mm}$ balloon that progressed over time $(\mathrm{E})$. The arrows indicate the area of vasospasm. F: Single-plane fluoroscopic view obtained after the vasospasm was successfully treated with intraarterial nitroglycerin and deployment of a $9 \times 30-\mathrm{mm}$ Precise stent, which required secondary angioplasty with a Cordis Slalom $5 \times 20-\mathrm{mm}$ balloon.

DPD and secondary angioplasty were identified as candidate variables $(p<0.25)$. They were entered into a multivariate model that yielded an area under the curve of 0.90 in the receiver-operator characteristic in its ability to predict vasospasm, but only the use of the first-generation fixed-basket FilterWire DPD was identified as an independent predictor of the incidence of vasospasm ( $p<0.0003)$.

\section{Discussion}

Since its introduction into clinical practice and initial results in the 1990s, there has been mounting evidence supporting CA stent placement as a therapy for CAD and as a potential alternative to surgical endarterectomy in certain high-risk patients. To validate CA stent placement as a safe treatment option for $\mathrm{CAD}$, the procedure should improve upon the natural history of CAD with respect to the incidence of stroke and be equivalent or superior to carotid endarterectomy with respect to safety and efficacy in the treated population. The potential for distal embolization of plaque fragments to the brain during $\mathrm{CA}$ stent placement spurred the development of a variety of distal embolization protection devices. ${ }^{13}$ The deployment of a stent in addition to angioplasty increases the occurrence of microembolic events as detected by transcranial Doppler sonography, ${ }_{1}$ potentially increasing the risk of thromboembolic complications. A systematic review in 2003 found that DPD appeared to reduce the number of thromboembolic complications of CA stent placement, ${ }^{10} \mathrm{a}$ view that was confirmed by a review that incorporates the results of several trials that have been completed since. ${ }^{22}$

While there seems to be an emerging consensus that CAS should only be performed with the use of DPDs, ${ }^{14}$ data exist that points out the risks and potential adverse effects of the use of a DPD. All DPDs are subject to slight proximal and distal movements during the procedure, even in the hands of the most experienced operators. ${ }^{11}$ Many filters, including the 3 DPD types used in this study, are guidewire mounted. This same wire provides the basis for the exchange of the devices used through the primary angioplasty, stenting, and secondary angioplasty phases of CA stent placement. Advancement and retrieval of balloons and stents and the DPD itself have the potential to cause movement of the DPD and damage to the delicate endothelium of the distal cervical ICA. Irritation or damage of the intima, ranging from self-limiting vasospasm to intimal dissection with occlusion of the vessel, can ensue acutely. ${ }^{4,12,19,25}$ Stone et al. ${ }^{24}$ report a $0.6 \%$ rate of dissection after using the FilterWire EX DPD in 348 interventions in aortocoronary bypass grafts. Keeping the DPD stable during the intervention necessitates frequent fluoroscopic position checks that prolong the procedure.

Five different cerebral protection devices were studied in an ex vivo porcine CA model, and the extent of the vessel wall damage caused during deployment, simulated adverse movement ( $1 \mathrm{~cm}$ up, $2 \mathrm{~cm}$ down, and $1 \mathrm{~cm}$ up again), and retrieval was assessed histologically. All devices caused debris to dislodge during deployment and retrieval; the FilterWire EX caused partial endothelial damage in all instances but no subendothelial destruction. Adverse movement did not cause increased debris dislodgement. ${ }^{15}$ The second-generation mobile-basket DPDs that we used in our study were not available at the time the porcine model study was performed, and a follow-up study that incorporates these devices and other new DPDs such as the second-generation of the FilterWire DPD, the FilterWire EZ, would be valuable. Thus, DPDs themselves harbor the potential to cause distal thromboembolic complications, ${ }^{11,15}$ explaining the increased rate of microembolic signals on transcranial Doppler sonography in patients in whom a DPD had been used. ${ }^{11,26}$

We noted a high $(67 \%)$ incidence of ICA iatrogenic vasospasm associated with the use of the first-generation FilterWire DPD in the current study, which necessitated the modification of the conventional procedure to include intraarterial infusion of nitroglycerin in 3 cases and periods of 


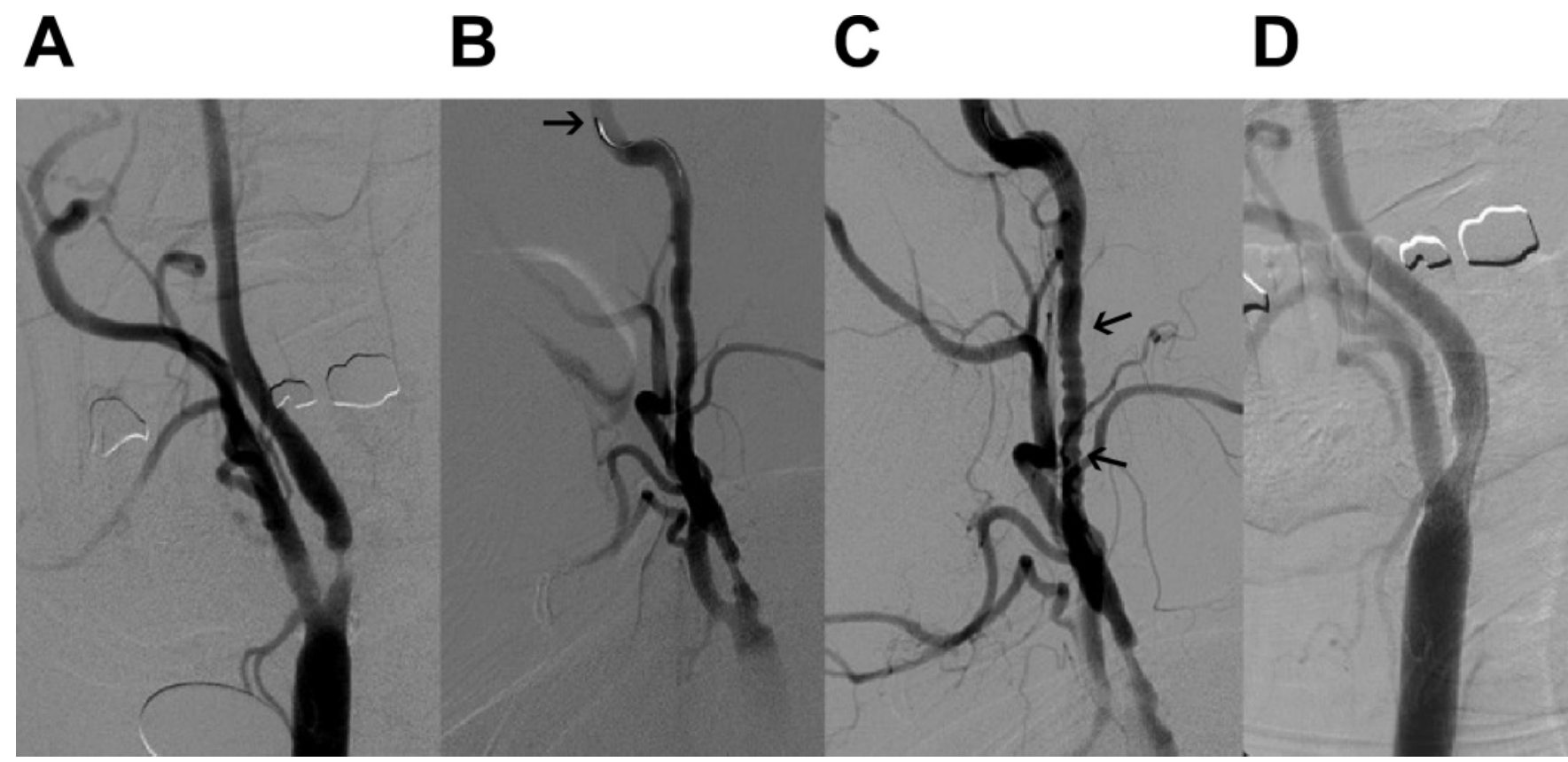

FIG. 3. Angiograms illustrating vasospasm during CA stent placement without DPD using a plain guidewire (A), focal high-grade stenosis of the cervical ICA (B), a bare wire advanced past the lesion into the petrous ICA segment (arrow), and (C) vasospasm of a long segment of the cervical ICA (arrows) that was self-limited and resolved without sequelae (D).

pause in order to wait for the vasospasm to resolve before proceeding to the next step.

The authors of the initial multicenter study reporting on the experiences with the FilterWire EX did not comment on the incidence of periprocedural vasospasm. ${ }^{8}$

Lack of vessel apposition with the FilterWire EX may allow embolic debris to bypass the filter and may be more prone to occur in the possibly tortuous CA. Orthogonal biplanar views are necessary to ensure vessel wall apposition and may be difficult to obtain. Additional manipulations of the FilterWire EX may be necessary to achieve an optimal position of the device, increasing the risk of vessel wall irritation. The next-generation version has been modified to allow the previously fixed basket to move independently from the guidewire shaft and is easier to position. ${ }^{24}$

All instances of vasospasm were self limited and reversed after the procedure was halted temporarily or, in 4 cases, after the administration of intraarterial nitroglycerin. In cases in which severe vasospasm is present proximal to the DPD, it is almost impossible to retrieve the DPD without causing further, potentially more serious injury to the vessel wall. Intraarterial nitroglycerin resolves vasospasm in most occurrences (in all instances in the current case series) and enables the operator then to perform a safe retrieval of the DPD or an exchange maneuver, depending on the stage of the procedure. This holds true even for cases in which no DPD was used and vasospasm was caused by guidewire manipulations.

The administration of intraarterial nitroglycerin, however, can cause a significant drop in blood pressure, which, in the setting of severe flow-limiting vasospasm, can lead to at least transient hypoperfusion of the downstream cerebral circulation $^{5}$ with potential ischemic sequelae. There were no permanent sequelae such as intimal dissection associat- ed with the FilterWire DPD, and there was no incidence of TIA or stroke following the procedure in our series of patients. A non-flow-limiting dissection was caused in a patient treated without distal protection. Deployment of a stent was not possible in this case, and primary angioplasty was performed; the dissection was observed and was not apparent on follow-up angiography.

There was no apparent relationship between the incidence of vasospasm and other technical factors such as the level of the distal tip of the microwire or whether it was above of below the C-1 vertebral body. In several cases the stiff distal tip of the DPD wire limited its use because of a tortuous CA or tonsillar loop.

A tortuous anatomy of the cervical CA also endangers safe retrieval of the DPD by putting a small segment of the distal tines of the stent into the lumen of the ICA and between the DPD and the retrieval catheter. This happened with oversizing of the stent or unanticipated changes in the vessel curvature after deployment of the stent. Deployment of the DPD distal to a sharp bend of the ICA also impaired retrieval of the DPD by coupling the forward motion of the retrieval catheter and the DPD, resulting in movement of the DPD prior to complete retrieval.

The findings of this study suggest that the first-generation DPDs, with fixed-basket construction, in contrast to bare guidewire or mobile-basket DPDs, induce significant iatrogenic injury to the target vessel. These findings should encourage the further development of novel, less traumatic DPDs that may not subject the endothelial wall to focal frictional irritation. The long-term consequences of focal vasospasm are not well known and angiographic follow-up may be needed to monitor the areas of DPD deployment to rule out delayed stenosis; this area is usually not covered by the follow-up ultrasonography used to monitor CA stenosis. 


\section{M. Schirmer, D. A. Hoit, and A. M. Malek}

TABLE 3

Univariate analysis of the incidence of vasospasm in relation to patient-specific and angiographic factors*

\begin{tabular}{lccl}
\hline \multicolumn{1}{c}{ Variable } & Total & Vasospasm Observed & p Value \\
\hline no. of procedures & 40 & 12 & \\
angiographic factors & & & \\
pre-CAS stenosis & $82 \pm 2.9$ & $81 \pm 1.8$ & $<0.84$ \\
any DPD & $18 / 40(45)$ & $12 / 18(67)$ & $<0.012 \dagger$ \\
fixed-basket FilterWire EX & $12 / 40(30)$ & $8 / 12(67)$ & $<0.001 \dagger$ \\
mobile-basket second-generation DPD & $6 / 40(15)$ & $1 / 6(17)$ & $<0.42$ \\
cervical loop & $12 / 40(30)$ & $5 / 12(42)$ & $<0.29$ \\
wire above C-1 & $18 / 40(45)$ & $6 / 18(33)$ & $<0.68$ \\
primary angioplasty & $33 / 40(83)$ & $11 / 33(33)$ & $<0.32$ \\
stent deployment & $37 / 40(93)$ & $12 / 37(32)$ & $<0.24$ \\
secondary angioplasty & $34 / 40(85)$ & $12 / 34(35)$ & $<0.03 \dagger$ \\
patient characteristics & & & $<0.71$ \\
age in yrs (mean \pm SD) & $71 \pm 10$ & $72 \pm 10$ & $<0.40$ \\
female sex & $16 / 40(40)$ & $6 / 16(38)$ & $<0.49$ \\
stroke/TIA & $20 / 40(50)$ & $5 / 20(25)$ & $<0.17$ \\
previous CEA & $4 / 40(10)$ & 0 & $<0.51$ \\
previous stent & $1 / 40(3)$ & 0 & $<0.60$ \\
asymptomatic & $20 / 40(50)$ & $7 / 20(35)$ & $<0.53$ \\
bilateral disease & $12 / 40(30)$ & $3 / 12(25)$ & $<0.29$ \\
previous radiation tx & $2 / 40(5)$ & $1 / 2(50)$ & $9 / 25(36)$ \\
hx of myocardial ischemia & $25 / 40(63)$ & & \\
\hline
\end{tabular}

$*$ Values represent numbers of procedures $(\%)$ unless otherwise indicated. tx $=$ therapy.

$\dagger$ Statistically significant.

\section{Conclusions}

A significantly higher incidence of iatrogenic vasospasm was observed following CA stent placement with the fixedbasket FilterWire EX compared with stent placement with a second-generation mobile-basket DPD or unprotected stent placement. While this phenomenon was self-limiting, vasospasm should be considered a risk of this type of DPD that may predispose to more serious vascular injury. Improvements of the DPD design, as seen in the secondgeneration devices in this study, mechanically uncouple the microwire from the filter element to limit force transmission and friction between the filter and vascular intima. When a DPD is elected during CA stent placement, preference should be given to a second-generation mobile-basket device to help minimize the risk of thromboembolic complications, vasospasm, and vessel wall injury.

\section{Disclaimer}

None of the authors of this paper has any financial interest in any of the devices described in this study.

\section{References}

1. Al-Mubarak N, Roubin GS, Vitek JJ, Iyer SS, New G, Leon MB: Effect of the distal-balloon protection system on microembolization during carotid stenting. Circulation 104:1999-2002, 2001

2. Anonymous: Endovascular versus surgical treatment in patients with carotid stenosis in the Carotid and Vertebral Artery Transluminal Angioplasty Study (CAVATAS): a randomised trial. Lancet 357:1729-1737, 2001

3. Bosiers M, Peeters P, Verbist J, Schroë H, Deloose K, Lauwers G, et al: Belgian experience with FilterWire EX in the prevention of embolic events during carotid stenting. J Endovasc Ther 10:695-701, 2003

4. Cardaioli P, Giordan M, Panfili M, Chioin R: Complication with an embolic protection device during carotid angioplasty. Catheter Cardiovasc Interv 62:234-236, 2004
5. Cottrell JE, Gupta B, Rappaport H, Turndorf H, Ransohoff J, Flamm ES: Intracranial pressure during nitroglycerin-induced hypotension. J Neurosurg 53:309-311, 1980

6. Gil-Peralta A, Mayol A, Marcos JR, Gonzalez A, Ruano J, Boza F, et al: Percutaneous transluminal angioplasty of the symptomatic atherosclerotic carotid arteries. Results, complications, and follow-up. Stroke 27:2271-2273, 1996

7. Gray WA, Hopkins LN, Yadav S, Davis T, Wholey M, Atkinson $\mathrm{R}$, et al: Protected carotid stenting in high-surgical-risk patients: the ARCHeR results. J Vasc Surg 44:258-268, 2006

8. Grube E, Colombo A, Hauptmann E, Londero H, Reifart N, Gerckens U, et al: Initial multicenter experience with a novel distal protection filter during carotid artery stent implantation. Catheter Cardiovasc Interv 58:139-146, 2003

9. Henry M, Amor M, Masson I, Henry I, Tzvetanov K, Chati Z, et al: Angioplasty and stenting of the extracranial carotid arteries. J Endovasc Surg 5:293-304, 1998

10. Kastrup A, Gröschel K, Krapf H, Brehm BR, Dichgans J, Schulz JB: Early outcome of carotid angioplasty and stenting with and without cerebral protection devices: a systematic review of the literature. Stroke 34:813-819, 2003

11. Macdonald S: Is there any evidence that cerebral protection is beneficial? Experimental data. J Cardiovasc Surg (Torino) 47: 127-136, 2006

12. Macdonald S, Venables GS, Cleveland TJ, Gaines PA: Protected carotid stenting: safety and efficacy of the MedNova NeuroShield filter. J Vasc Surg 35:966-972, 2002

13. Markus HS, Clifton A, Buckenham T, Brown MM: Carotid angioplasty. Detection of embolic signals during and after the procedure. Stroke 25:2403-2406, 1994

14. Mas JL, Chatellier G, Beyssen B, EVA-3S Investigators: Carotid angioplasty and stenting with and without cerebral protection: clinical alert from the Endarterectomy Versus Angioplasty in $\mathrm{Pa}$ tients With Symptomatic Severe Carotid Stenosis (EVA-3S) trial. Stroke 35: E18-E20, 2004

15. Müller-Hülsbeck S, Stolzmann P, Liess C, Hedderich J, Paulsen F, Jahnke T, et al: Vessel wall damage caused by cerebral protection devices: ex vivo evaluation in porcine carotid arteries. Radiology 235:454-460, 2005 


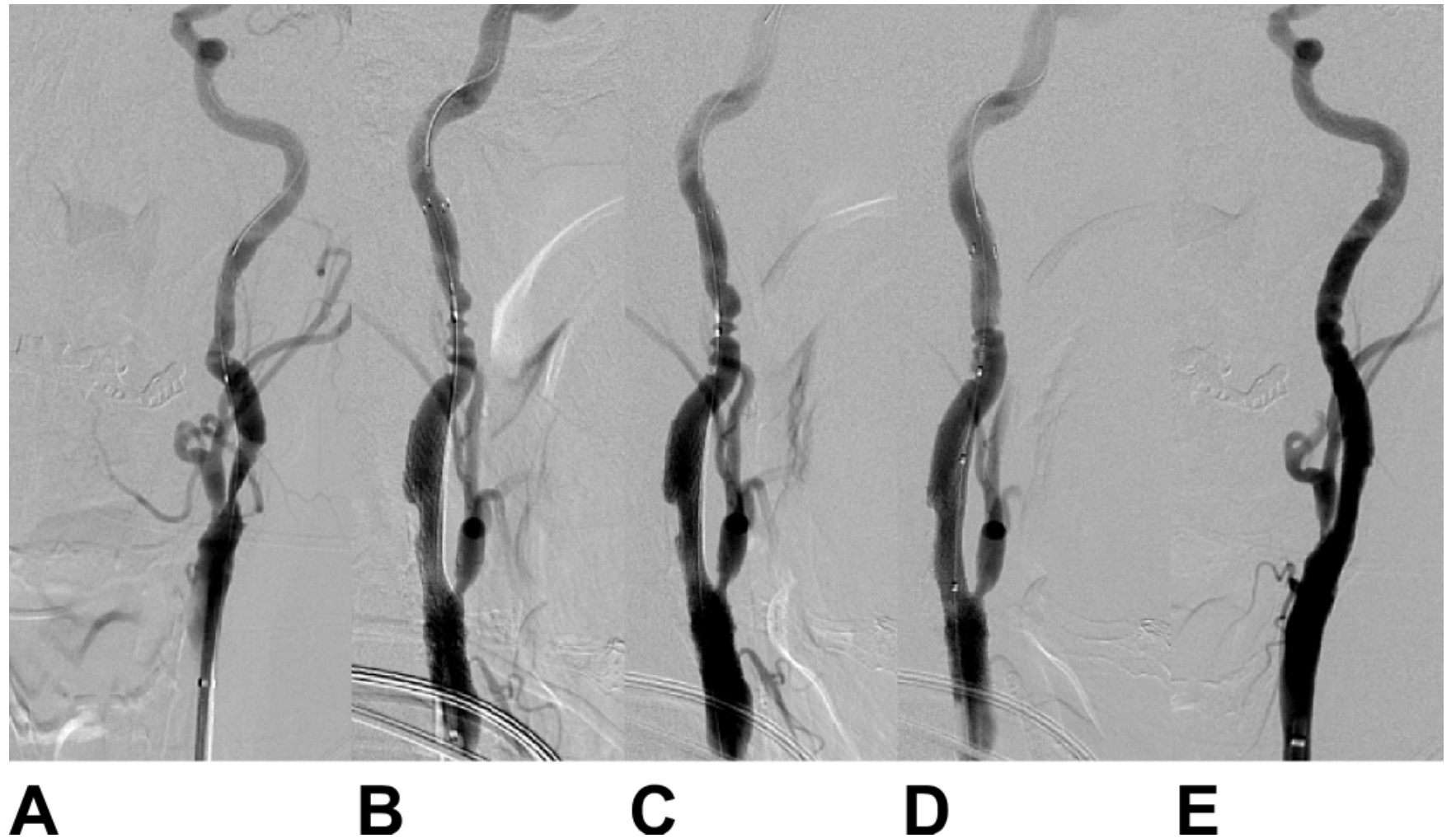

FIG. 4. Angiograms obtained during a CA stent placement procedure using a second-generation RX Accunet DPD in a 71-year-old woman with extensive cardiac risk. A: Single-plane angiographic image of a left ICA stenosis that was followed up over time and progressed to $>80 \%$ (as determined by angiography). B-D: Iatrogenic vasospasm after deployment of the DPD and placement of a 40-mm Guidant Acculink stent. E: Resolution after intraarterial administration of nitroglycerin.

16. Ohki T, Roubin GS, Veith FJ, Iyer SS, Brady E: Efficacy of a filter device in the prevention of embolic events during carotid angioplasty and stenting: an ex vivo analysis. J Vasc Surg 30: 1034-1044, 1999

17. Ohki T, Veith FJ: Carotid stenting with and without protection devices: should protection be used in all patients? Semin Vasc Surg 13:144-152, 2000

18. Ohki T, Veith FJ: Critical analysis of distal protection devices. Semin Vasc Surg 16:317-325, 2003

19. Reimers B, Schlüter M, Castriota F, Tübler T, Corvaja N, Cernetti $\mathrm{C}$, et al: Routine use of cerebral protection during carotid artery stenting: results of a multicenter registry of 753 patients. Am J Med 116:217-222, 2004

20. Roubin GS, New G, Iyer SS, Vitek JJ, Al-Mubarak N, Liu MW, et al: Immediate and late clinical outcomes of carotid artery stenting in patients with symptomatic and asymptomatic carotid artery stenosis: a 5-year prospective analysis. Circulation 103:532-537, 2001

21. Safian RD, Bacharach JM, Ansel GM, Criado FJ: Carotid stenting with a new system for distal embolic protection and stenting in high-risk patients: the carotid revascularization with ev3 arterial technology evolution (CREATE) feasibility trial. Catheter Cardiovasc Interv 63:1-6, 2004

22. Schonholz CJ, Uflacker R, Parodi JC, Hannegan C, Selby B: Is there evidence that cerebral protection is beneficial? Clinical data. J Cardiovasc Surg (Torino) 47:137-141, 2006

23. Shawl F, Kadro W, Domanski MJ, Lapetina FL, Iqbal AA, Dougherty KG, et al: Safety and efficacy of elective carotid artery stenting in high-risk patients. J Am Coll Cardiol 35:1721-1728, 2000
24. Stone GW, Rogers C, Ramee S, White C, Kuntz RE, Popma JJ, et al: Distal filter protection during saphenous vein graft stenting: technical and clinical correlates of efficacy. J Am Coll Cardiol 40:1882-1888, 2002

25. Tan WA, Bates MC, Wholey MH: Cerebral protection systems for distal emboli during carotid artery interventions. J Interv Cardiol 14:465-474, 2001

26. Vos JA, van den Berg JC, Ernst SM, Suttorp MJ, Overtoom TT, Mauser HW, et al: Carotid angioplasty and stent placement: comparison of transcranial Doppler US data and clinical outcome with and without filtering cerebral protection devices in 509 patients. Radiology 234:493-499, 2005

27. White CJ, Iyer SS, Hopkins LN, Katzen BT, Russell ME, BEACH Trial Investigators: Carotid stenting with distal protection in high surgical risk patients: the BEACH trial 30 day results. Catheter Cardiovasc Interv 67:503-512, 2006

28. Wholey MH, Wholey M, Mathias K, Roubin GS, Diethrich EB, Henry M, et al: Global experience in cervical carotid artery stent placement. Catheter Cardiovasc Interv 50:160-167, 2000

29. Wholey MH, Wholey MH, Tan WA, Toursarkissian B, Bailey S, Eles G, et al: Management of neurological complications of carotid artery stenting. J Endovasc Ther 8:341-353, 2001

Manuscript submitted November 15, 2007.

Accepted December 5, 2007.

Address correspondence to: Adel M. Malek, M.D., Ph.D., Department of Neurosurgery, Tufts-New England Medical Center, 750 Washington Street \#178, Proger 7, Boston, Massachusetts 02111. email: amalek@tufts-nemc.org. 